\title{
The Archive's Moment
}

\section{Lila Caimari}

check for updates

Citation: Caimari, L. The Archive's Moment. Histories 2021, 1, 100-107. https://doi.org/10.3390/

histories 1030013

Academic Editor: Jon Mathieu

Received: 31 March 2021

Accepted: 21 June 2021

Published: 4 July 2021

Publisher's Note: MDPI stays neutral with regard to jurisdictional claims in published maps and institutional affiliations.
Consejo Nacional de Investigaciones Científicas y Técnicas, Universidad de San Andrés, Buenos Aires B1644BID, Argentina; lcaimari@udesa.edu.ar

\begin{abstract}
This article summarizes observations on the "archive question" as it manifests itself in Argentina at the present moment. Based on a presentation delivered in Buenos Aires, it opens with a general appraisal of the multiple dynamics (political, disciplinary, technological) converging on this issue. Then, it focuses on a particular dimension of this process-namely, the impact of the digital archive on the reconstruction of the Argentine past.
\end{abstract}

Keywords: archive history-digital reproduction

\section{Introduction}

This article offers a number of observations on the "archive question", as they appear from the point of view of a socio-cultural historian interested in the situation of Argentine archives, and the place of archives in historical research as a whole. It is not based on any expert knowledge; I am neither an archivist nor a specialist by any definition. Rather, my goal is to outline ideas born from a specific vantage point at a moment of much-increased interest on the subject.

Of course, the casual conversation about the archive has always existed. I refer to the one that combines enjoyment and suffering, the serendipitous find and the tale of catastrophe, topics that have a long tradition in the disaster genre born of the sorry state of archives in our country. What prompts new reflection on the matter is that against that entrenched backdrop, we find a host of developments that have brought to the archive a cluster of new, heterogeneous meanings.

Each day brings a new example of the trend. When evaluating applications for research agencies, for example, one notices a proliferation of projects that are true plans of recovery and access to old archives and libraries. Such projects are now accepted as a legitimate way to enter CONICET (National Institute for Scientific and Technical Research (Consejo Nacional de Investigaciones Científicas y Técnicas), Argentina). Additionally, at CONICET, we are currently witnessing the birth of a Network of Archives and Document Management, as well as new initiatives linking researchers and preservation institutions, or institutions in possession of sensitive archives in need of professional counsel. Meanwhile, we receive a plethora of flyers for talks and seminars, with titles featuring the word "archive" (or one of its derivations) to designate a wide repertoire of objects and practices that previously fell under other rubrics. Suddenly, everything seems to have become an archive, or has been "touched" by the archive, or evokes it in some way. Not so long ago, this would have been unimaginable. The archive was the world's least fashionable theme. The juxtaposition of the words "archive" and "trend" would have been almost absurd.

I will begin by broadly describing some elements of what we might call the "Archive's Moment", a convergence of global and local trends that outline particular points of inflection, distinct from the "Archival Turn", as has been called in other contexts. I will then focus on a specific diagnosis linked to my field, socio-cultural history, and what I see as a relevant symptom of the current relationship between archives and research. 


\section{Intersections}

In this intense yet diffuse surge of interest in the archive, one may distinguish the intersection of several processes that allow for an initial outline. First, at a very basic level, we see increased awareness about the need for the care and preservation of archives and the professionalization of their management. Second, and simultaneously, there is a growing discussion about our relationship with the archive as researchers, a development which in turn is embedded in a renewed interest in reflecting and writing about the craft of history. Third, there have emerged some specific subfields-such as a media history of technology - which also include the question of the archive. This inflection can be traced back to the history of print and reading (the Chartier-Darnton path, we might say (I am referring, of course, to French historian Roger Chartier and US historian Robert Darnton, both leading scholars in the history of books and reading.), which is currently being carried on in questions about technology, media, and communication, in the study of the practices born of the transition from one medium to another, as well as in the revolution in our relationship with the written word. We also see a proliferation of methodological projects on the practice of research within this new environment. Finally, at the base of many other trends, there is a wide avenue of more abstract representations of the archive. This multiple use of the term is the product of the intersection of critical theory- $\mathrm{I}$ am thinking, of course, of the influential early work of Michel Foucault, beginning with The Archaeology of Knowledge (1969) [1]; of Jacques Derrida's Archive Fever (1995) [2]; of some passages in Michel De Certeau's The Writing of History (1975) [3], among others-and the transformation of the definition of the archive due to technological changes, by way of a long series of intermediate stations and particular translations. This explosive encounter between critical theory and technological revolution has given rise to what is often called the Archival Turn. From this seismic movement emerges the association of countless disciplinary, intellectual, and even artistic practices with an "archive" that has become a malleable instrument. A theoretical tool, then, a category as well as an object, the archive is today a vast repertoire of operations, with widespread uses in literary theory, in the world of fiction, in cultural criticism, in the visual arts ...

Let us consider, then, a landscape in which all these elements are more or less intertwined, sometimes in the same panel, in the same work team, or in the same committee. The convergence of movements, different in content and institutional nature, finds in this polysemic figure the inspiration for projects, expectations, and demands: discussions on management policy, essays on cultural theory, historiographic narratives, methodological manuals, aesthetic-political projects, etc.

A common element underlies all of this: arriving by different paths, the archive has become a politically powerful point of reference and has taken its place in the public agenda. One might argue that it has always been so, that CeDInCI (Centro de Documentación e Investigación de la Cultura de Izquierdas. Founded in Buenos Aires in 1998, CeDInCI was conceived as a non-profit civil association devoted to the preservation of the cultural heritage of the Left), for example, was exactly that: the archive as a (political) instance of the retrieval of subaltern voices, of points of view outside of the mainstream. Later on, in the context of the Argentine trials for crimes against humanity, the archive (or certain archives, at least) found its moment of maximum political relevance. An important link was born between archive and collective memory, turning it into a prolific area of reflection. This connection is a foundational element of regional conceptions of the archive, and not just in the Southern Cone. I am reminded of the book edited by Carlos Aguirre and Javier Villa-Flores on the destruction and recovery of archives in Latin America (From the Ashes of History, Loss and Recovery of Archives and Libraries in Modern Latin America, 2015) [4], which contains essays on numerous countries. There is also Kirsten Weld's work (Paper Cadavers, 2014) [5], a study falling somewhere between academic research and political intervention of the extraordinary retrieval process of police archives in Guatemala. We know that there are echoes of this movement in other genres, such as documentary filmmaking on the collective memory of the 1970s, where the archive occupies an important place as well. The 
recent Chilean documentary, Historia de mi nombre (Karin Cuyul, 2019) [6], for example, combines reverberations of that 1970s archive with more contemporary understandings of it, based on the search for intimate childhood archives-photo albums, home movies-by the "second generation", that of the children of victims of military violence.

Coupled with this, a new cohort of experts has turned the archive into a place of advocacy, a movement involving significant changes in the culture of institutional staff, and which reveals parallel transformations in the world of archival expertise. During my time as a student, the archive was a politically inert place. No one dreamed of changing the world from within those quiet stacks. Today they are the battleground of a fast-growing community of politically engaged archivists, where the link between technical capacity and political power of the archive is a given.

One does not need to encounter such explicit connections to notice that, no matter how disparate, all the threads evoking the archive denote the loss of naiveté (political, conceptual, methodological) about the object. In the world of history, the cultural change in the ways of conceiving the archival institution is readily apparent. The increased awareness here calls us to intervene by using our public voice to draw attention to the problems in this field while at the same time acknowledging the importance of delegating the work to experts. Not only do we see the Argentine Association of History Researchers placing the issue at the core of its agenda, addressing complaints and requests, but a more recent and more far-reaching example can be found in the aforementioned interdisciplinary network implemented by CONICET, an ambitious program aimed at promoting public policies and discussions on the archive. It no longer occurs to anyone (except political authorities, who continue to lag far behind in the debate) that committing oneself to the cause of the archives implies taking control of the archive. There are other ways of intervening. Of course, the battle for professionalization has not yet been won, and the problems of policy discontinuity and fragmentation of agendas are still there, as destructive as ever. However, despite all this, there is a new consensus, a trend that seems irreversible.

There has also been a shift from the traditional understanding of the history-archive relationship. The notion of the "auxiliary" discipline, as it was described to us years ago at the university, is now seen as almost comical in light of what archival discipline has become, and of the current status of information science. Not only is there no hierarchical relationship, but there is also no exclusivity, for we are facing the shattering of the traditional connection between archives and history. The "archive question" cuts across many disciplines-including disciplines outside the humanities. Additionally, nor are academic researchers the sole beneficiaries. Another premise that has gained ground is that of the public archive as an instance of the exercise of public rights: in addition to documents for research into the past, there are the land titles of native peoples, the legacies of state repression, the documentation of immigrant ancestors, among many others.

What role do we, as researchers, have to play in this transformation? It is clear that ours is not to manage the archives, nor to build them in the traditional sense. However, neither is it simply to benefit from them (though not everyone needs to become a champion of the archive, and fortunately, it is still perfectly acceptable to maintain an instrumental, joyful, and carefree relationship with this space). There are new, more informed avenues of intervention, instances that reflect directly or indirectly this new documentary awareness - from the more explicit political awareness of the public archive to the more subtle relationship between archive and creation, archive and writing, born of contact with particular collections, with epistolary corpora, etc.

Some features of this relationship intersect with other lines of development. It is here where we see the semantic expansion of the category "archive", the entry of this term into an infinite number of micro-processes, the landscape that has allowed its transmutation into a figure, a metaphor, a tool. Interestingly, this impulse does not come so much from history, nor from its rather craft-like traditional relationship with the archive, but from fields where the question has entered more recently and by other channels, such as literature. 
Some will say that there was always Ricardo Piglia, our writer most interested in the archive (Argentine writer and literary critic, Ricardo Piglia (1941-2017) was initially trained as a historian at the National University of La Plata, and maintained a keen interest in the work of history, in the interpretative construction of the past, and in the fruitful potential of the archive as a place of documentary accumulation.). However, what we see now has a different theoretical basis, another focus. Piglia thought of the archive as a given, as an object of fascination for its infinite potential, but the origin and the structure of this universe were not subject to interrogation. By contrast, numerous critical analyses pivot around a broad and dynamic notion of the archive. The recent book by Juan José Mendoza, Los Archivos. Papeles para la nación (2019) [7], illustrates some possible uses of the concept with a range of themes and approaches to the question as understood by a literary researcher shaped in this context. It offers a diverse catalog in steady conversation with the history of books and reading: a personal map, open in its possibilities. In a different vein, Graciela Montaldo's latest book, Museo del consumo. Archivos de la cultura de masas en la Argentina (2015) [8], opens by turning the construction of the archive underlying this ambitious project into a problem, one that is entirely different from the notion of "I have an original archive". What is included and what is not, why, and with what criteria, to say what and discuss it with whom: the term appears as a way to broaden the predictable base, as a defiant movement of inclusion of non-consecrated materials, as a tool to examine the canon. In yet another sense, Valeria Luiselli's novel Lost Children Archive (2019) [9] displays several archival figures in its plot while also citing the main constellation of theoretical essays on the subject. In this road novel, the story of a family crossing the United States is organized in a plot taking place in a car, with material archives (those carried by each member in a box in the trunk), immaterial archives (the sound archives of decimated communities, which they hope to rescue in the desert) and an archive produced along the way, through the voices of the children who comment on the terrible news of the moment. Diverse as they are, these cases indicate an awareness (conceptual, political) of the countless underlying operations involved in the shaping of archives of all kinds, as well as of their effects.

Meanwhile, we see other manifestations of this moment in our academic world through the growing number of projects about private collections and increased efforts to trumpet their value. It is a shift coupled with another shift. These projects tend to emphasize public access as a horizon and as an aspiration: the archive (whether received or created) is not only not a secret, but its accessibility now becomes a major topic of discussion. A growing share of resources seems to gravitate towards creating or developing access to collections, something which was not even considered until recently. Each team creates its archive for its own benefit, and that of those who come after, a pattern that suggests the weakening of the individual and secret notion of such possession and researchers' new engagement with the problems of the archive. All this is due, of course, to the technological possibilities that allow for the delocalization and democratization of access. Additionally, here again, we find the emerging emphasis on expertise in the form of newly incorporated archival consultancies in humanities projects.

Underlying these transformations, then, are the possibilities offered by a world where each individual has become a daily creator and reproducer of online files (archivos). The fact that the same old Spanish word has been chosen to designate computer-generated units has created an explicit conceptual continuity between the tangible and the intangible archive. It has also spilled over into fields and disciplines far beyond those that traditionally included this reference. It would be impossible to fully account for this development, the ramifications of which extend to so many areas and activities. To identify some symptoms, I will only note the growing amount of literature on the effects of this change on research practices. These analyses of tools go beyond the question of technical assistance, to interrogate the role of these instruments in the ways we work and think, and the opportunities and eventual pitfalls they pose in their path. I mention only two widely cited cases in our field: Anaclet Pons's El desorden digital. Una Guia para historiadores y humanistas 
(2013) [10]; and Lara Putnam's critical-methodological warnings in "Transnational and the Text-Searchable. Digitized Sources and the Shadows They Cast" $(A H R, 2016)$ [11].

This corpus suggests, moreover, that even the reflections made by historians for historians are somehow embedded in the broader question of the construction of knowledge, and thus in the underlying manifestations of power inscribed in the design of structures and connections. In other words, today, we see a relatively complex set of views of the archive as construction, which shows the fruits of the long road of theory, its relationship with media studies, and its culmination (through many mediations) in a common sense that is also less naïve on this level.

I notice a specific feature of this movement in Argentina: the awareness of the implications of the archive, the presence of the "archive question" in projects on such diverse themes; all of this combines elements that in other contexts have remained separate. On the one hand, we see an increased drive toward the generation of "archontic" authority, in the form of efforts to institutionally strengthen existing archives, to train human resources, and to allocate subsidies for the creation of funds: an impulse to create more archives in a context of precarious, neglected or non-existent archives. This impetus appears together with a critical distance with the object born from the (mostly) French theory of the archive-whose authors, as we know, did not need to worry about the matter since they were inspired by archives built by ancien régime states over many centuries. Thus, the projects involving the construction and development of archives occur in the context of increased awareness not only of the professionalizing and democratizing mandates but also of their theoretical and epistemological implications. In these lands of fragile or absent archives, the critical consciousness of the archive is not incompatible with public projects aimed at the creation and growth of "archontic" responsibility. It could hardly be otherwise, since, as in other fields, the reception of critical theory takes place without the objects that inspired it. This is why it is important that this process also establishes its own theoretically and methodologically informed line of reflection, sensitive to its singular conditions of existence.

This environment has also been fertile to the cultivation of writings on the research process, reminiscent of the reflections of Arlette Farge [12] (I am referring to the classic The Allure of the Archive, published in 1989, a book that has taken on a new life). Here, the archive is no longer a mere repository of material waiting to be discovered: it is not the intellectually less prestigious (laborious, opaque) aspect of the work of historians but rather a creative instance conducive to reflection and writing. This interest is intertwined with a parallel awareness of the discursive operations of historical narrative and also engages in the broader constructivist sensibility. Behind-the-scenes archive writing is developing increasingly within the framework of methodological teaching. This is also the context of Ivan Jablonka's reflections (in particular, History is a Contemporary Literature. Manifesto for the Social Sciences, 2016) [13], conceived with one foot in academia and the other in essay writing. Between two best-sellers that narrate firsthand the process of researching true cases, Jablonka returns to the discipline to discuss writing as an expressive tool of history. At the end of a long historiographic reckoning, his bet on a revival of the historian's writing vitality focuses, above all, on the intellectual and moral adventure of research.

This trend reappears in the growing world of history projects aimed at a broader public, such as those podcasts where the process and the product of research are discussed simultaneously. In France, for example, France Culture's popular broadcast, "La Fabrique de l'Histoire", bears the question of the making of history in its very title. Additionally, in the United States, Jill Lepore's podcast, "The Last Archive", evokes criminal cases of the past alongside the history of the investigation, drawing on a host of sound resources reminiscent of radio drama. The staging of the research process is organized here around the archive as a place of truth in times of fake news. Lepore works with a traditional notion of the archive, which gains special significance in the American political context. In any case, let us take note of the narrative approach to the archive by historians dedicated to communication outside the academy. 


\section{Pathways to Digitization and Views of the Past}

Within this broad context, I would like to focus on an underrepresented yet relevant topic in countries such as Argentina: namely, the implications of the changed definition of the archive on historiography itself and the reconstruction of the past. I return here to the effects of delocalization for researchers situated on the periphery of this process, and I draw on one of the works included in the collection edited by Antoinette Burton (Archive stories. Facts, Fictions and the Writing of History, 2005) [14]. In this compilation of stories on the construction of archives, Renée Sentilles' essay ("Toiling in the Archives of Cyberspace") considers the implications of digital archiving in developing countries and the question of digital absence-as opposed to the more usual reflection about digitization and access (and excess). She also considers the effects of digitization in under-archived societies, where the process grows from precarious infrastructures, and wonders about the implications of the web as a system of archival visibility. The article discusses disappearing elements, fragility, areas of silence. Hence, her argument is in favor of the digitalization of archives in non-central countries. I return to it because since then (2005), the issue has become more relevant, and because, as in so many areas, the context of the pandemic has highlighted it as never before.

I am interested in framing Sentilles' question within the issue of the construction of the digital corpus of Argentine culture, and the concrete effects that partial projects have on the whole. I will start with a personal example, which I know is far from exceptional. During the months of quarantine, I worked on a book that I had committed to some time before. This book, which drew from a previous line of research on the history of the Argentine press in 1900, was premised on the idea that I would spend a considerable part of 2020 in newspaper archives in Buenos Aires. The archives closed, and are still closed as I write these lines. I waited, and then waited some more, and in the end, after asking for extensions, I started to look for alternatives that were accessible from my bunker, just as so many others did.

Several things appeared in the process, but not the ones on which I based my original proposal. I had to radically alter the project to adapt it to the documents available under these circumstances. In other words, what was going to be a book based on evidence obtained from newspapers (an object that had a certain kind of presence in nineteenthcentury life), has become a study on illustrated magazines, an object that is different but much more accessible because it is easier to digitize and upload online.

We may think of these as works marked by the pandemic. I consider them to be more than that. When the newspaper archives open, many projects will be underway and follow their independent paths. However, more importantly, what appears to be an anomaly illustrates, in truth, a preexisting trend that is accelerating dramatically and has consequences for our discipline. I had written about this myself several years ago in relation to the historiographical effects of the (very fortunate) incorporation of the popular weekly Caras y Caretas into the digital archive of the National Library of Spain (La vida en el archivo. Goces, tedios y desvios en el oficio de la historia, 2016) [15]. With the increasing rate of removal of physical newspapers from the time of that magazine, and in the absence of digitally accessible substitutes, the effect of this availability has only increased.

With the acceleration of this shift, it has become more apparent that the conversation about the archive cannot be separated from the question of digitization policies. Note that I am not referring to methodological questions: that is, to the reasons why it is important to maintain physical contact with documents, or the repercussions of the transition to digital media, or the ballooning of academic resources, or the weakening of the relationship with those sources. All these problems are part of a change that is extraordinary in its possibilities, and it is with good reason that so much is being said about them. Lately, I am more interested in the question of the general biases of the corpus and in the historical hypotheses that are emerging from a map that is increasingly shaped by issues of access, which are very unequal from one medium to another, from one country to another, from one 
type of source to another: a more general reflection on the history of cultural consumption being written amid this change.

The fact that studies on Buenos Aires newspapers become studies on illustrated magazines means that these newspapers (i.e., the most widely read printed product of the time) are left out, distorting our understanding of the actual reading practices and public conversations, not to mention the other aspects of the newspaper as a structuring agent of nineteenth- and twentieth-century culture. Additionally, this happens, moreover, when the question of circulation (of information, ideas, fiction, and representations) has become central to so many projects.

The underlying problem was always there, of course: there was never equal access to anything - the archive is selective and discontinuous by definition. However, what remains in the shadows today is even more obscured by its contrast with what can be easily accessed online. I continue with the symptoms in my field: the history of the South American press has benefited enormously from the uploading of the Brazilian newspapers thanks to the National Library of Brazil, which took on the job very early on. We all celebrated the event, of course. However, it so happens that Brazil was the only country in the region with a project of this magnitude, a state-run project. Neither Chile, Argentina, nor Uruguay has anything comparable to this corpus as of yet. Years have passed, and the historiographic effects are plain to see. Not only is there an absolutely disproportionate proliferation of studies of the Brazilian press in universities in the northern hemisphere. The reference to Brazil (Rio de Janeiro in particular) as the main pole of the modern press in the Southern Cone in the nineteenth and early twentieth centuries has also been growing. In the recent books on the global history of the press, chapters on this region never fail to focus on Brazil. All this happens, as we know, despite basic indicators that say otherwise-not only that the center of the modernization of the press was in the Rio de la Plata, where its most important readership markets were, etc., but that it was an integrated system, difficult to comprehend without its regional articulations. In the meantime, the Rio de la Plata newspaper collections remain in the shadows, the available items receive more and more attention, and the bias deepens by the day.

It does not seem necessary to give further examples because the point is clear. The challenge is not simply to create more digitized online archives. The map that these archives produce is also important to our understanding of these societies' past. Access to certain documentary universes has grown remarkably without the development of a remotely comparable base (which is more costly to digitize, no doubt) that could provide context, a sense of the scale and distribution of readership as it was at the time we are studying. This distortion demands a much greater effort to weigh the relative influence of each piece on the whole, given that there are basic corpora of Argentine culture that are completely out of reach. This is where the nature of this development becomes clear, as well as the limits of the hopes for a digitizing wave that would allow overcoming the historical precariousness of Argentine archives and libraries (national, but also provincial, for these biases have a great impact at this level as well).

Let me be clear: thankfully there are some good projects of digital resources-América Lee, AHIRA, and many others, more specific and modest (Historical Archive of Argentine Magazines (Archivo Histórico de Revistas Argentinas, https: / / ahira.com.ar/, access on 15 May 2021; América Lee, http:/ / americalee.cedinci.org/, access on 15 May 2021). Fortunately, there are foreign libraries that fill in some of the gaps. However, this constellation of bright spots is arranged according to their own inclinations, with selective criteria that are always interesting, but that do not take into account the effect of proportion on a larger map. We have a wealth of socialist magazines just two clicks away; we can access from anywhere cultural publications we thought were lost forever; we can browse through very rare newspaper collections, curious gems, some works of genius (and some not so much). However, we do not have (either digitally or in paper) the most widely read newspapers-some of which were also extraordinary. Thus, the constellation is arranged around a vacuum, because this sum of partial projects cannot replace a coordinated policy 
of construction of the digital corpus of Argentine culture. This gap is already reflected in the views of the past that are being produced today.

\section{Conclusions}

I would not want to close this intervention by feeding into apocalyptic views. On the contrary, I would instead reaffirm that we are in a moment of exceptional convergence of energies, one which allows us to open up discussions as never before. These observations are born from the conviction that there are indeed areas in which researchers' criteria still have a place. The agendas of this "Archive's Moment" will necessarily be scattered in different disciplines and settings (public, private, state, civil society). What emerges from them will also require cross-disciplinary conversations.

Funding: This research received no external funding.

Institutional Review Board Statement: Not applicable.

Informed Consent Statement: Not applicable.

Data Availability Statement: Not applicable.

Conflicts of Interest: The author declares no conflict of interest.

\section{References}

1. Foucault, M. L'Archéologie du Savoir; Gallimard: Paris, France, 1969.

2. $\quad$ Derrida, J. Mal D'Archive. Une Impression Freudienne; Galilée: Paris, France, 1995.

3. De Certeau, M. L'Écriture de L'Histoire; Gallimard: Paris, France, 1975.

4. Aguirre, C.; Villaflores, J. (Eds.) From the Ashes of History, Loss and Recovery of Archives and Libraries in Modern Latin America; University of North Carolina Press: Chapel Hill, NC, USA, 2015.

5. Weld, K. Paper Cadavers. The Archives of Dictatorship in Guatemala; Duke University Press: Durham, NC, USA, 2017.

6. Cuyul, K. Historia de mi Nombre. (Documentary). Chile-Brazil. 2019. Available online: https://www.youtube.com/watch?v= PTqsGB9km78 (accessed on 1 May 2021).

7. Mendoza, J.J. Los Archivos_. Papeles para la Nación; Eduvim: Villa María, Argentina, 2019.

8. Montaldo, G. Museo del Consumo. Archivos de la Cultura de Masas en Argentina; Fondo de Cultura Económica: Buenos Aires, Argentina, 2015.

9. Luiselli, V. Lost Children Archive. A Novel; Knoprf: New York, NY, USA, 2019.

10. Pons, A. El Desorden Digital: Guía para Historiadores y Humanistas; Siglo XXI Editores: Madrid, Spain, 2013.

11. Putnam, L. The Transnational and the Text-Searchable: Digitized Sources and the Shadows They Cast. Am. Hist. Rev. 2016, 121, 377-402. [CrossRef]

12. Farge, A. Le Goût de L'Archive; Seuil: Paris, France, 1989.

13. Jablonka, I. L'Histoire est une Littérature Contemporaine. Manifeste pour les Sciences Sociales; Seuil: Paris, France, 2014.

14. Burton, A. Archive Stories. Facts, Fictions and the Writing of History; Duke University Press: Durham, NC, USA, 2005.

15. Caimari, L. La Vida en el Archivo. Goces, Tedios y Desvíos en el Oficio de la Historia; Siglo XXI Editores: Buenos Aires, Argentina, 2016. 